\title{
Appropriate Technology: Manual Rotary Table Concept for Water Drilling in Nigeria
}

\author{
${ }^{1}$ Mohammed U. Jibrin, ${ }^{2}$ Ibrahim O. Abdulmalik, ${ }^{1}$ Michael C. Amonye, \\ ${ }^{1}$ Mahdi Makoyo and ${ }^{2}$ Akonyi N.S \\ ${ }^{I}$ National Board for Technology Incubation, (Federal Ministry of Science and Technology), Abuja, Nigeria. \\ ${ }^{2}$ Hydraulic Equipment Development Institute (HEDI), National Agency for Science and Engineering \\ Infrastructure (NASENI), (Federal Ministry of Science and Technology), P.M.B 3067, Kano Nigeria.
}

\begin{abstract}
Groundwater development through construction of water wells forms the nuclei of government and international donor agencies intervention programmes in the rural and semi-urban areas. These wells are drilled using hand-digging, human powered drilling rigs, imported and locally fabricated small and large conventional drilling rigs. The efforts of indigenous rig fabricators have improved access to water in Nigeria, but their equipment majorly lacking in engineering design soon breakdown after commissioning. While they work, their operations are usually cumbersome and stressful with random breakages of drill stems and drill bits. The trend has persisted to the degree that progress in water prospecting has become the race of three steps forward and four steps backwards. The National Board for Technology Incubation and the Hydraulic Equipment Development Institute both of the Federal Ministry of Science and Technology, in keeping with their intersecting mandates of bringing technology to the grassroots and developing hydraulic machines respectively; in 2011, instructed this project in the following terms: "By reviewing existing human powered drilling methods, develop a more efficient technology with reduced human horsepower requirement capable of achieving up to 50meters depths in the low depth aquifers scattered across the country."
\end{abstract}

Key Words: water, manual drilling, technology, technology incubation.

\section{INTRODUCTION}

The current practice in manual drilling in Nigeria is shown in FIGURE 1 is a rotary method of manual drilling. A four or three way clamp and pipe wrenches are used to turn the drill stem in the clockwise direction to achieve drilling. It is easily seen that the operators are struggling with friction on all sides as they rotate the drill stem to execute boring. This is due to lack of concentricity during the pipe descent into the hole. At any point in time, the drill stem can dangle to any side with the possibility of taking cuts in slightly slanting positions. Drilling becomes tedious and a struggle with both the earth and the tools.

Breakages of drill bits and stems are common place with the resultant production of awkward holes which are liable to fail shortly after commissioning, as the attendant evasion from the drudgery does not lend the operators the patience to work to rich aquifers. This research evolved and developed a new technology which amongst other features ensures the following.

1. That cutting must be centrically executed, with even cuts by the bit lips.

2. That the drill stem is positioned equidistance and concentric with the hole being made by the bits.

3. Easy mobility of the rotating stem through the installation of a bearing assembly and the utilization of a Kelly in the square slot of the bearing assembly for drilling.

This technology excludes the possibility of boring in the slanting position. It also excludes any friction that would have been occasioned by the drill stem touching or resting on the walls of the bore. More than anything, it ensures that the energy spent in turning the stem is purely utilized in cutting soil, regolith and rock. 


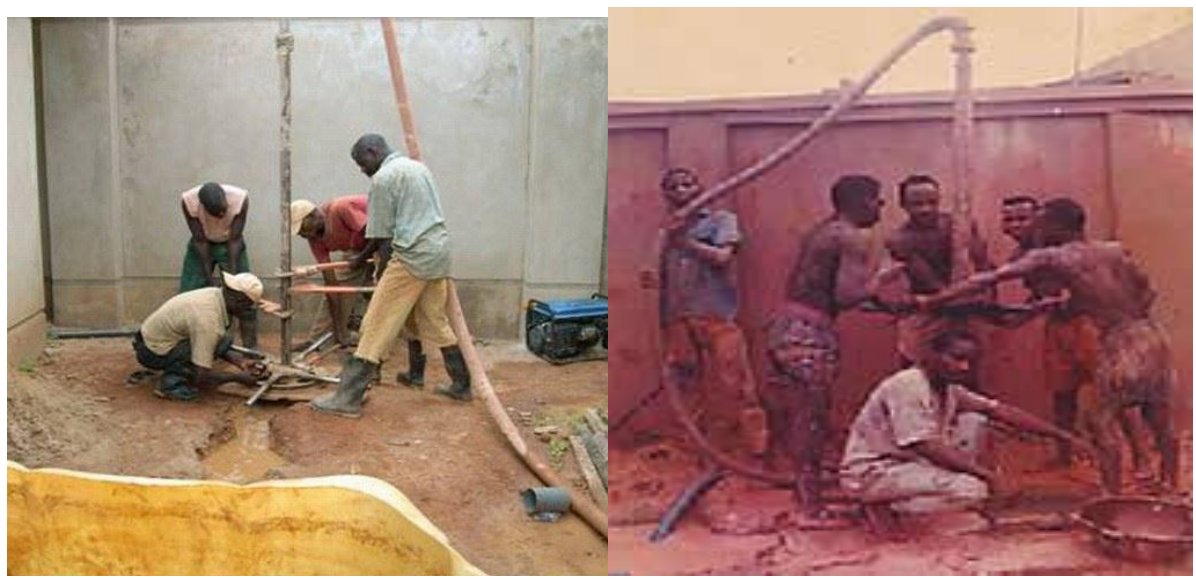

FIGURE 1: Current manual water drilling in Nigeria

\section{DESIGN OF THE MANUAL ROTARY TABLE CONCEPT}

The design considerations that guided the project in the critical areas of drilling power and stanchion capability are discussed hereunder. The winch and wire rope selection are based on the manufacturer's specification of 3 tones $(3000 \mathrm{~kg})$ and matching wire rope.

\section{1: Strength of soils and rocks}

Unconfined Compressive Strength (UCS) of a rock or soil is defined as the strength of the rock or soil sample when crushed in one direction without lateral strain. Unconfined Compressive Strength is also referred to as Uniaxial Compressive Strength. It is a primary index in determining the drillability of a formation as well as in determining the most suitable drilling or excavation method for any formation. It is the strength of a rock or soil sample when crushed in one direction (uniaxial) without lateral restraint. (Allaby and Allaby 1999).

The UCS of non-cohesive soils cannot be measured since the sample will crumble on drying. Soils are classified into types A, B, and C according to a report by BS-121(2009); ASTM standards D653-85 and D2XSS.

Type A soils are of UCS 144KPa and above Type B soils are of UCS between 48KPa and 144KPa while, Type $\mathrm{C}$ soils are of $48 \mathrm{KPa}$ UCS or less. Rocks are classified by strength with the gradient measuring from soft completely weathered rocks of the sedimentary family to the very hard metamorphic and igneous rocks. Accordingly very weak rocks are of UCS between 1.25 and $5 \mathrm{MPa}$; weak rocks are classified as rocks of UCS less than $12.5 \mathrm{MPa}$; rocks of medium strength has UCS between $12.5 \mathrm{MPa}$ and $50 \mathrm{MPa}$. Strong rocks have UCS of between 50MPa and 100MPa while very strong rocks have UCS between 100MPa and 200MPa. Rocks of UCS above 200MPa are graded as extremely strong rocks (Hawkins 1998). Weak rocks comprise of some weakly compacted sedimentary rocks or some very highly weathered igneous or metamorphic rocks. Medium strength rocks comprise of some foliated metamorphic rocks and highly weathered igneous and metamorphic rocks. Strong rocks comprise low grade metamorphic rocks and marbles while very strong rocks are mainly of plutonic, hypabyssal and extrusive igneous rocks.

\section{2: Design analysis of the concept}

Three distinct actions are evident in rotary drilling

(a) The rotary motion which cuts and chips the rock or earth

(b) The sliding down of the drill string which claims the depth drilled

(c) The flushing which cools the bits and removes debris.

Thus a driller should ensure among other things the employment of a mud pump with enough pressure for the maximum depth and size of hole intended. A sizeable Weight On Bit (WOB) is also necessary to ensure a simultaneous sliding of the drill string as the hole is cut. WOB is the total weight of the drill pipes and the bit executing the drilling. Drilling is achieved by the sliding and rotary actions of the drill bit. The drilling power required at the bit is given by: (Zacny and Cooper, 2007)

$$
\mathrm{POWER}_{\text {DRILLING }}=\mathrm{POWER}_{\text {SLIDING }}+\text { POWER }_{\text {CUTTING }} \quad------(1.1)
$$

a) POWER OF SLIDING

Effective force of sliding

$\mathrm{F}_{\text {SLIDING }}=\mu \mathrm{x}$ WOB

Hence effective sliding torque 
$\mathrm{T}_{\text {SLIDING }}=$ Force $\mathrm{x}$ Distance $=\mu \times \mathrm{WOB} \times \mathrm{R}_{\mathrm{C}}$

Where,

WOB $=$ Weight on bit.

$\mathrm{R}_{\mathrm{C}}=$ Radius of centre of pressure of the cutting elements of the bit.

$\mu=$ coefficient of sliding friction.

Thus

$\mathrm{POWER}_{\text {SLIDING }}=\mathrm{TORQUE}_{\text {SLIDING }} \mathrm{x} \mathrm{W}$ rads/sec

$$
=\left(\mu \times \mathrm{WOB} \times \mathrm{R}_{\mathrm{C}}\right) \times(2 \pi / 60 \times \mathrm{RPM})
$$

b) POWER OF CUTTING

Work done or energy expended in crushing a volume of rock is given by

$\mathrm{E}_{\mathrm{ROCK}}=\mathrm{UCS} \times \mathrm{V}$ joules.

$$
=\mathrm{UCS} \times \pi \mathrm{D}^{2} / 4 \times \mathrm{d}_{\mathrm{PR}}
$$

Power to break a rock is

$$
\text { POWER }_{\text {CUTTING }}=\text { WORK }_{\text {PER REVOLUTION }} \times(2 \pi / 60 \times \text { RPM }) \text { watts }
$$$$
=\left(\mathrm{UCS} \times \text { Area } \times \mathrm{d}_{\mathrm{PR}}\right) \times(2 \pi / 60 \times \mathrm{RPM}) \text { watts }
$$

Where

$$
\begin{aligned}
& \text { Area }=\pi / 4\left(\mathrm{D}_{\text {out }}^{2}-\mathrm{D}_{\text {IN }}^{2}\right) \quad\left(\mathrm{m}^{2}\right) \\
& \mathrm{D}_{\text {OUT }}=\text { Outside diameter of cutting element of the bit. }(\mathrm{m}) \\
& \mathrm{D}_{\mathrm{IN}}=\text { Inner diameter of the cutting element of the bit. }(\mathrm{m}) \\
& \mathrm{UCS}=\text { Unconfined compressive stress of the rock. }\left(\mathrm{N} / \mathrm{m}^{2}\right) \\
& \mathrm{d}_{\mathrm{PR}}=\text { Depth of cut per revolution. }(\mathrm{m}) \\
& \mathrm{RPM}=\text { Rotational speed in revolutions per minute. }
\end{aligned}
$$

c). TOTAL DRILLING POWER

Total drilling power in rotary drilling is given by:

$$
\text { POWER }_{\text {DRILLING }}=\left(\mu \times \text { WOB } \times R_{C}\right) \times(2 \pi / 60 \times R P M)+\left(U C S \times \text { Area } \times d_{P R}\right) \times(2 \pi / 60 \times R P M
$$

\subsection{Drilling power computation (POWER DRILLING) )}

Equation 1.6 above gives drilling power, which is

POWER $_{\text {DRILLING }}=(\mu \times$ WOB x R $) \times(2 \pi / 60 \times$ RPM $)+\left(\right.$ UCS x Area $\left.\times d_{P R}\right) \times(2 \pi / 60 \times$ RPM $)$---- (1.7).

Drilling is saddled with constantly varying parameters. The whole terrain starts with differing degrees of soil and regolith and transverses through differing types of rocks. Where investigations show soil and rock samples, the Unconfined Compressive Stress (UCS) of the strongest rock is used in computation. As the terrain varies, the coefficient of sliding friction $(\mu)$ and depth of cut $\left(\mathrm{d}_{\mathrm{pr}}\right)$ per revolution vary simultaneously as drilling progresses. The Weight On Bit (WOB) varies progressively on each addition of a drill stem.

In motorized drilling, three parameters of the Drilling Power Equation are closely constant. These are the radius of the center of pressure of the cutting elements of the bit (Rc) which is usually approximated as the average radius of the bit, the cutting area of the bit (Area) and the Revolutions per minute (RPM). However in manual drilling the Revolution per minute (RPM) is steadily changing. It is adduced that minimum and maximum revolutions per minute of 10 and 20 respectively can be achieved on a manual drilling rig.

For the 6inches $(152.4 \mathrm{~mm})$ carbide drag bit shown in FIGURE 3, the average radius $(\mathrm{Rc})$ and cutting area are estimated as follows:

$$
\begin{aligned}
\mathrm{Rc} & =0.1524+0.0254 / 2=0.0889 \mathrm{~m}---------(1.8) \\
\text { Area } & =\pi / 4(0.15242-0.02542)=0.0177 \mathrm{~m} 2 .-------(1.9)
\end{aligned}
$$

Coefficient of sliding friction is estimated from friction measurement of tungsten carbide bit on nugget sandstone with mud as drilling fluid. The highest value of 0.04 is taken. (Finger and Glowka, 1989). 


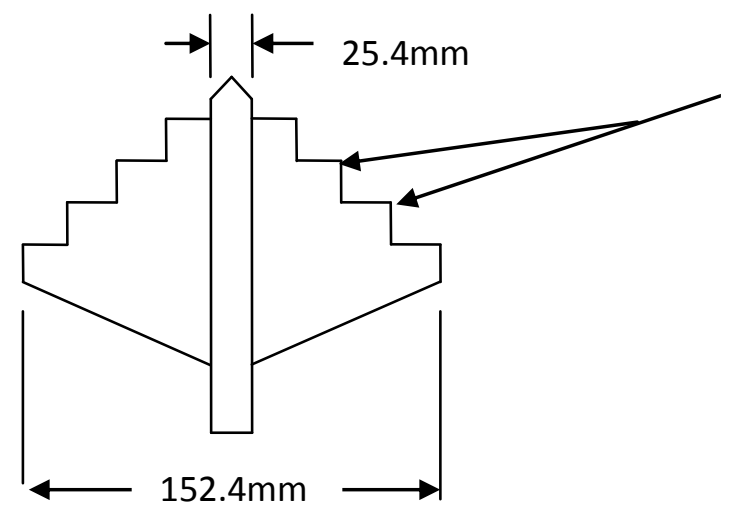

BIT CUTTING LIPS

FIGURE 2: Drag bit

\subsubsection{Depth of cut $\left(d_{\mathrm{pr}}\right)$}

Take the effective drilling time during one day as eight hours. Take time of change of pipe and the time of drilling to be equal. Time of effective drilling per day is fours. Take five days of drilling to do a maximum of 50 meters. Time for rotary drilling equals 20hours. Which is $20 \times 60$ minutes $=1200$ minutes or 12000 revolutions at 10rpm. Projected depth of cut per revolution:

$$
\mathrm{d}_{\mathrm{PR}}=50 \times 1000 / 12000=4.22 \mathrm{~mm}
$$

\subsubsection{Unconfined Compressive Stress (UCS)}

From equation 1.6, the Unconfined Compressive Stress (UCS) of the strongest rock particle in such formation is:

$$
\begin{gathered}
U C S=\frac{60 \times\left(\mathrm{POWERD}_{\text {RILLING }}\right)-(\mu \times \text { WOB } \mathrm{xC}) \times(2 \pi / 60 \times \mathrm{RPM})}{2 \times \pi \times R P M \text { Area } x d_{P R}} \\
\qquad C S=\frac{60 \times[140-(0.04 \times 5886 \times 0.0889) \times(2 \times \pi \times 10 / 60)]}{2 \times \pi \times 10 \times 0.017 \times 0.00422}=1.51 \mathrm{MPA}
\end{gathered}
$$

Inference from above UCS shows that the equipment is suited for drilling in predominantly soil and very weak rock formations.

Estimated human power for work is given as 70watts (Compell, 1990). The construction of manual made easy rig shows that equipment shall be powered by two humans with total power output of 140 watts. Putting the following parameters $\left[\mu=0.04\right.$, WOB $=5886 \mathrm{~N}, \mathrm{R}_{\mathrm{c}}=0.0889 \mathrm{~m}$, Area $=0.0177 \mathrm{~m}^{2}$ and $\left.\mathrm{d}_{\mathrm{pr}}=0.00422 \mathrm{~m}\right]$ in equation 1.6, the drilling power (optimum terrain) for manual made easy rig can be computed.

\section{4: Stanchion design}

The draw works of the manual rotary table concept comprises a four legged stanchion of steel pipe section and a 50:1 velocity ratio winch and wire rope assembly. The drilling stanchion is shown in FIGURE 2. It was designed to carry the weight of drill pipes ordinarily called drill stems, and the bit up to a depth of more than 60 meters. The drill stems are pipes of $2.375 \mathrm{inch}(60.325 \mathrm{~mm})$ diameters, $10 \mathrm{ft}(3.048 \mathrm{~m})$ length and of mass approximately equal to $66.5 \mathrm{lb}(30 \mathrm{~kg})$. The stanchion legs are made of pipes $2.95 \mathrm{inch}(75 \mathrm{~mm})$ external diameter, $2.56 \mathrm{inch}(65 \mathrm{~mm})$ internal diameter and $18 \mathrm{ft}(5.49 \mathrm{~m})$ length. 


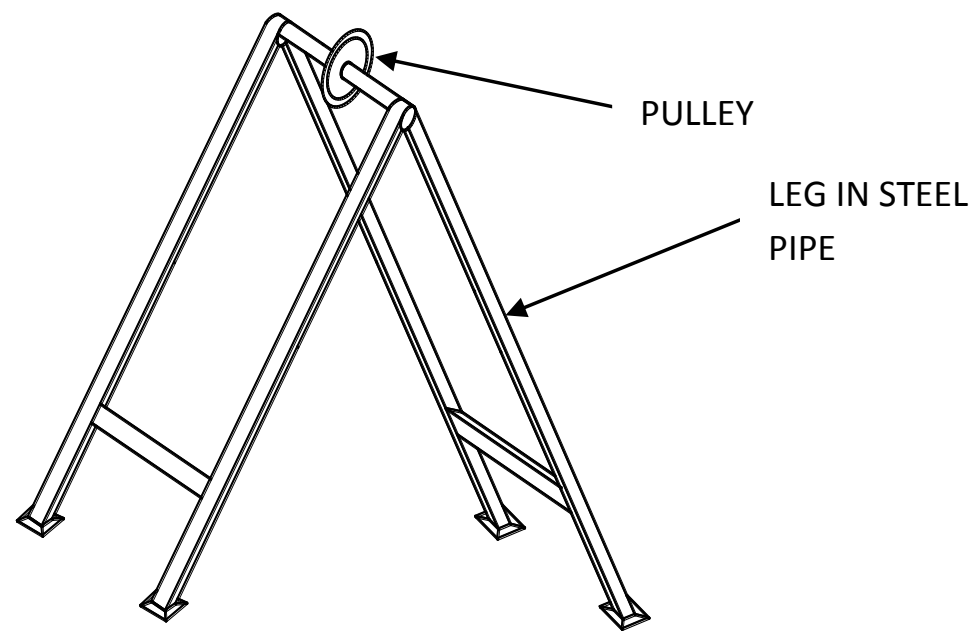

FIGURE 3: Drilling stanchion

The four legged stanchion carries the load of the drill stems and bit during the entire period of drilling. The legs are thus subjected to compressive stresses and taken as columns.

The parameter that determines which value of compressive stress to employ in structural evaluation of a column is the slenderness ratio which is the ratio of the effective length of the column to the least radius of gyration of the section. (Khurmi 1968).

Slenderness Ratio $(\mathrm{S})$ is given as

$$
\begin{aligned}
& \mathrm{S}=\mathrm{L}_{\mathrm{e}} / \mathrm{k}
\end{aligned}
$$

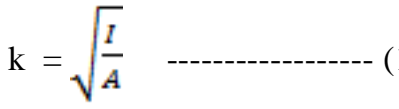

For hollow pipes

$$
\begin{aligned}
& A=\pi / 4\left(D^{2}-d^{2}\right) \\
& I=\pi / 64\left(D^{4}-d^{4}\right)
\end{aligned}
$$

Where,

$\mathrm{L}_{\mathrm{e}}=$ Effective or equivalent Length of Column.

$\mathrm{k}=$ Least radius of gyration.

$\mathrm{I}=$ Moment of Inertia.

$\mathrm{A}=$ Area.

$\mathrm{D}=$ External Diameter of pipe.

$\mathrm{d}=$ Internal diameter of pipe.

Both the slenderness ratio and the permissible stress are computed through an empirically determined fixture of effective or equivalent lengths depending on the end conditions of a column. The fixture for the stanchion is that of a column with one end fixed and the other hinged. Its equivalent length for structural analysis and computation is given as:

$$
\mathrm{Le}=\mathrm{L} / \sqrt{2}
$$

The choice of length of drill stem of $10 \mathrm{ft}(3.048 \mathrm{~m})$ is predicated on the common standard lengths in the market: $10 \mathrm{ft}, 15 \mathrm{ft}$, $20 \mathrm{ft}$ for water Drilling and $30 \mathrm{ft}$, $40 \mathrm{ft}$, $60 \mathrm{ft}$ and $100 \mathrm{ft}$ for oil drilling. The $10 \mathrm{ft}$ length elects a Kelly length of about $3 \mathrm{ft}$ longer to take care of back-fill during the period of drill stem replacement. The height of the manual rotary table underlines the minimum height of stanchion leg of $18 \mathrm{ft}(5.49 \mathrm{~m})$.

\section{Stanchion pipes design}

Two thick steel pipes were considered for application.

(a) 2.95inches $(75 \mathrm{~mm})$ Diameter steel pipe of $5 \mathrm{~mm}$ thickness

(b) 1.875 inches $(47.6 \mathrm{~mm})$ Diameter steel pipe of $4 \mathrm{~mm}$ thickness. 
Equivalent length (Le)for the two pipes is as follows

$$
\mathrm{Le}=\mathrm{L} / \sqrt{2}
$$

Where, $\mathrm{L}=18 \mathrm{ft} \times 12 \times 25.4=5486.4 \mathrm{~mm}$

$$
\text { Le }=5486.4 / \sqrt{2}=3879.5 \mathrm{~mm}
$$

Slenderness Ratio (S)

$$
\mathrm{S}=\mathrm{Le} / \mathrm{k}
$$

Where, $\mathrm{k}=$ least radius of gyration

$$
\mathrm{k}=\sqrt{\frac{I}{A}}
$$

Where, $\mathrm{I}=$ moment of Inertia of section $\mathrm{A}=$ Area of section

For Pipe (a) 2.95 inches $(75 \mathrm{~mm}) \times 5 \mathrm{~mm}$

$$
\begin{aligned}
\mathrm{I} & =\pi / 64\left(\mathrm{D}^{4}-\mathrm{d}^{4}\right)=\pi / 64\left(75^{4}-65^{4}\right)=676,915 \mathrm{~mm}^{4} . \\
\mathrm{A} & =\pi / 4\left(\mathrm{D}^{2}-\mathrm{d}^{2}\right)=1099.56 \mathrm{~mm}^{2} \\
\mathrm{~K} & =\sqrt{\frac{676915}{1099.56}}=\sqrt{615.6}=24.8 \mathrm{~mm} \\
\mathrm{~S} & =3879.5 / 24.8=\underline{156.4}
\end{aligned}
$$

For Pipe (b) 1.875 inches $(47.6 \mathrm{~mm}) \times 4 \mathrm{~mm}$

$$
\begin{aligned}
& \mathrm{I}=\pi / 64\left(\mathrm{D}^{4}-\mathrm{d}^{4}\right)=\pi / 64\left(47.6^{4}-39.6^{4}\right)=131286.3 \mathrm{~mm}^{4} \\
& \mathrm{~A}=\pi / 4\left(\mathrm{D}^{2}-\mathrm{d}^{2}\right)=\pi / 4\left(47.6^{2}-39.6^{2}\right)=547.9 \mathrm{~mm}^{2} . \\
& \mathrm{K}=\sqrt{\frac{I}{A}}=\sqrt{\frac{131286.3}{547.9}}=\sqrt{239.62}=15.48 \mathrm{~mm} \\
& \mathrm{~S}=3879.5 / 15.48=250.6
\end{aligned}
$$

From Khurmi 1968, the allowable compressive stress $\sigma_{c}$ for pipe (a) is $45.46 \mathrm{~N} / \mathrm{mm}^{2}$ and for pipe (b) is 17.4 $\mathrm{N} / \mathrm{mm}^{2}$. The allowable compressive stress of pipe (a) is about three times that of pipe (b). This is the basis for selection and utilization of the $75 \mathrm{~mm} \times 5 \mathrm{~mm}$ pipe in the stanchion construction. The universal stress equation is hereunder employed to determine the safe load.

$$
\sigma_{\mathrm{c}}=\mathrm{P} /(\text { Area })
$$

Where, $\mathrm{P}=$ Safe load $(\mathrm{N})$ and Area $=$ Area $\left(\mathrm{mm}^{2}\right)$

Hence

$$
\mathrm{P}=\operatorname{Area}\left(\mathrm{mm}^{2}\right) \times \sigma_{\mathrm{c}}\left(\mathrm{N} / \mathrm{mm}^{2}\right)=1099.56 \times 45.46 \times 10^{3} \mathrm{~N}=49.98 \times 10^{3} \mathrm{~N}
$$

Total Load for $60 \mathrm{~m}$ depth using $3.048 \mathrm{~m}$ length of $30 \mathrm{Kg}$ pipes

Number of Pipes $=60 / 3.048$

$$
\begin{aligned}
& =19.68 \\
& \cong 20 \text { Lengths }
\end{aligned}
$$

Weight $=20 \times 30 \times 9.81 \mathrm{~N}=5886 \mathrm{~N}$

Weight on each leg $=1471.5 \mathrm{~N}$

This is $1 / 33$ of the safe load for the leg. 


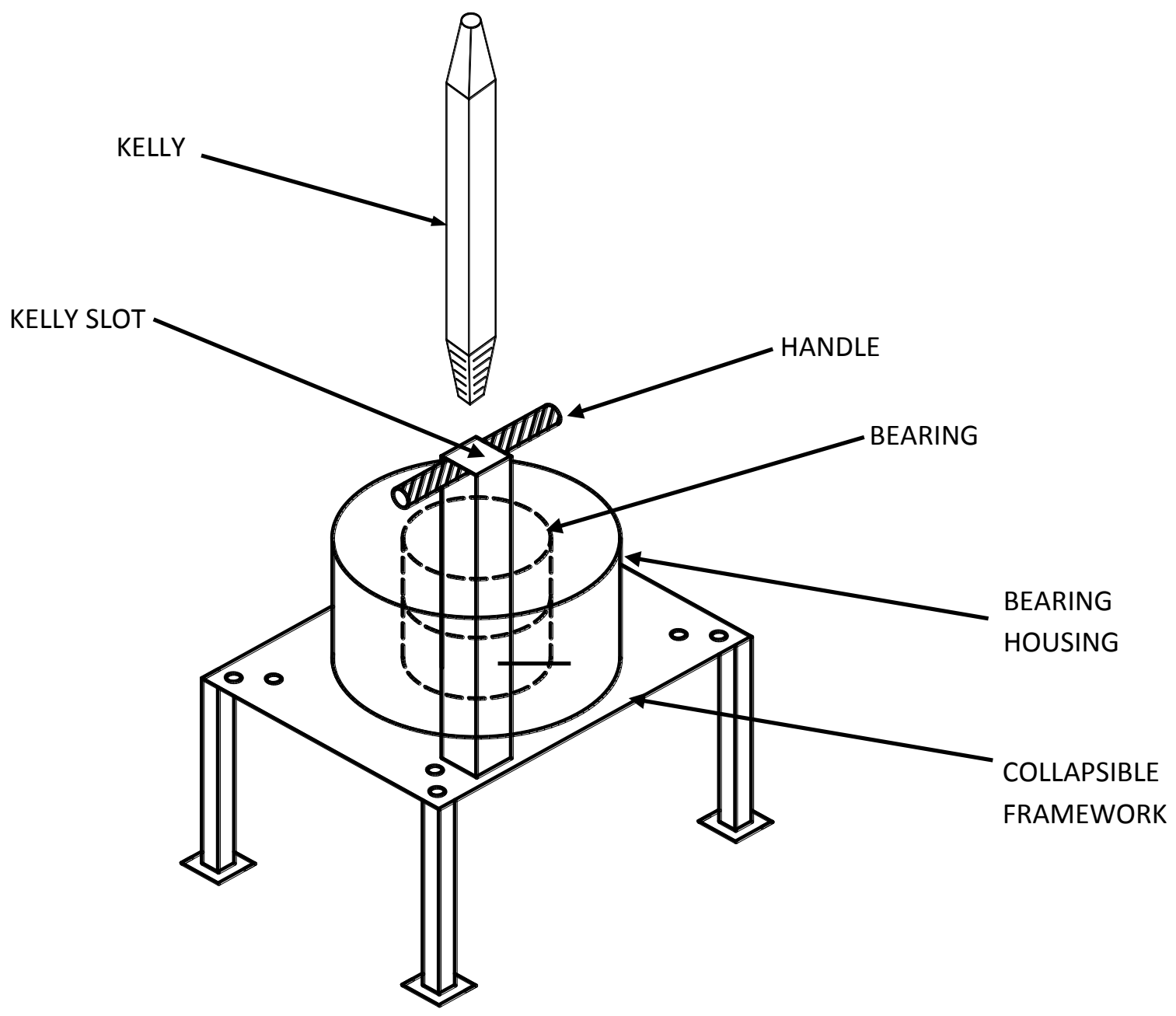

FIGURE. 4: Manual rotary table concept

\section{THE CONSTRUCTED ROTARY TABLE TECHNOLOGY}

The constructed equipment is presented in FIGURE 4. The figure depicts the important components of the manual rotary table technology. The manual rotary table contrivance is an installation of a square or multi-sided pipe arranged to rotate in ball bearings when it is turned on handles attached to it. Reduction in friction during turning and maintenance of concentricity and evenness of cuts are achieved. A square or multi-sided drill stem called kelly is constructed to rotate with the multi-sided pipe during operation. The drill bit and drill stems are attached to the lower end of the Kelly during drilling. 


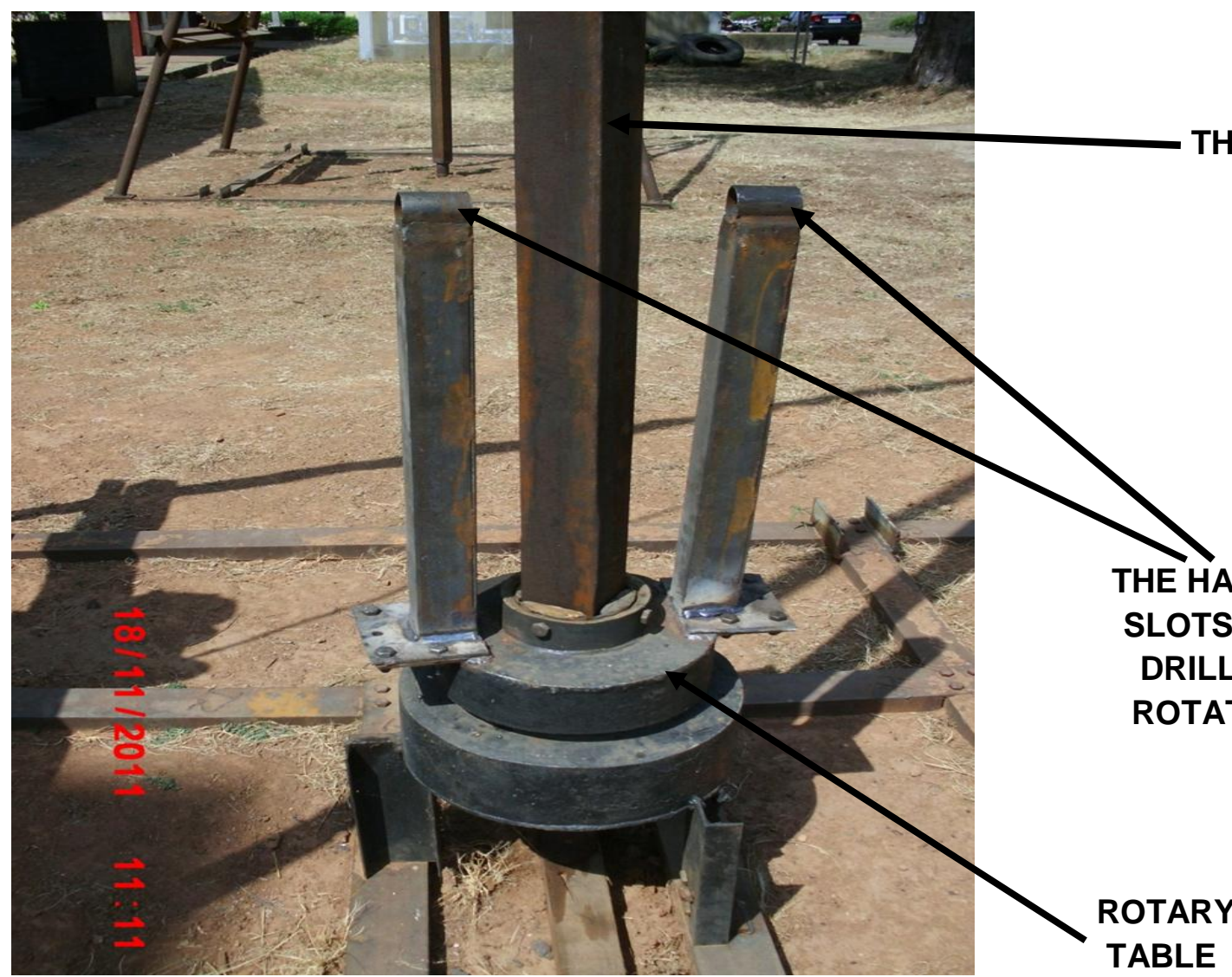

FIGURE 5: Constructed rotary table technology

\section{CONCLUSION}

The machine can be employed for drilling in soil and very weak rock formations. The human capability can execute depths up to a maximum of 60 meters. The stanchion has the static capability to carry loads ten times the design depth of sixty meters. It is however recommended for not more than two times the design depth to allow for a factor of safety of fifteen for dynamic working conditions. The winch of three tonnes capacity can carry load twice the WOB for the 60meter depth. It has been put to use since the test run in 2012 and found to have obvious advantages over the current manual methods.

\section{REFERENCES}

[1]. Allaby A and Allaby M (1999). A Dictionary of Earth Sciences. Oxford University Press, UK

[2]. ASTM (2009), Report BSS-121 (2009), American Society for Testing Materials (ASTM) Standards D653-85 AND D2488; The Unified Soils Classification System; The US Departments of Agriculture (USDA) Textural Classification Scheme; and The National Bureau of Standards.

[3]. Finger J. T and Glowka D. A (1989). PDC Bit Research at Sandia National Laboratories. Sandia Report SAND89-0079* UC-253; United States Department of Energy, Contract DE-ACDA-76DP00789.

[4]. Hawkins A. B (1998). Aspects of Rock Strength. Bull Eng Geol Env vol.57, p17-30.

[5]. Khurmi R. S (1968). Strength of Materials., Ram Nagar, New Delhi - 110055; pp 795-819.

[6]. Kris A Zacny and George A. Cooper (2007): Coring basalt under mars low pressure conditions. The International Journal of Mars Science and Exploration. MARS 3, p.1-11.

[7]. Sims B.G. and O'neil D. H. (2002). Aspects of Work Animal use in semi-arid Farming systems. European Association of Animal Production (E.A.A.P). 53 ${ }^{\text {RD }}$ Annual Meeting, Cairo Egypt, pp 4. 